\section{A Leach Collection System to Track the Release of Nitrogen from Controlled-release Fertilizers in Container Ornamentals}

\author{
Brian A. Birrenkott, ${ }^{1}$ Joseph L. Craig, ${ }^{2}$ and George R. McVey ${ }^{3}$ \\ The Scotts Company, D.G. Scott Research Center, 14310 Scottslawn Road, \\ Marysville $\mathrm{OH} 43041$
}

Additional index words. slow-release fertilizer, nursery plants, pot plants, nitrogen efficiency

\begin{abstract}
A leach collection unit (LCU) was assembled to capture all leachate draining from a nursery container. An injection molded 2.8-L nursery container was plastic welded into the lid of a 7.6-L black plastic collection bucket so that the bottom $2.5 \mathrm{~cm}$ of the nursery container protruded through the lid. The LCU was designed to track total $\mathrm{N}$ release from CRFs without confounding effects of plant uptake or $\mathbf{N}$ immobilization. Total $\mathbf{N}$ released between any two sampling periods is determined by multiplying the $\mathrm{N}$ concentration in a leachate subsample $\times$ total leachate volume. The $L C U$ were placed in a container nursery area with overhead irrigation. LCU were thoroughly leached before sampling the leach solution. To study the effects of substrate on $\mathrm{N}$ leach rates, Osmocote $18.0 \mathrm{~N}-2.6 \mathrm{P}-9.9 \mathrm{~K}(8$ to 9 months $21^{\circ} \mathrm{C}$ ) was incorporated at $1.8 \mathrm{~kg} \mathrm{~N} / \mathrm{m}^{3}$ using a locally available, bark-based substrate or medium-grade quartz sand. The experiment was conducted at Scotts Research locations in Apopka, Fla., and Marysville, Ohio. Osmocote incorporated into either a barkbased substrate or sand resulted in similar $\mathrm{N}$ release profiles. Although substrate did not affect $\mathrm{N}$ leach rate, quartz sand was recommended as the substrate in the leach collection system for polymer-coated CRFs. Quartz sand is chemically and biologically inert, does not immobilize nutrients and has low ion exchange capacity compared to bark-based potting substrates. More than $\mathbf{9 0 \%}$ of the total nitrogen applied from Osmocote was recovered from leachate and unreleased $\mathrm{N}$ in fertilizer granules. This research has demonstrated the leach collection system as a reliable means to quantify nitrogen release rate of a polymercoated CRF under nursery conditions. The LCU, when used with a crop plant, allows nutrient budget and nutrient uptake efficiency to be determined for CRFs.
\end{abstract}

Controlled-release fertilizers (CRFs) are used extensively in container nursery production. MostCRFs used for container ornamentals are derived from polymer-coated fertilizers, in which water soluble fertilizer granules are encapsulated by a polymer. Polymer-coated CRFs are categorized by manufacturers according to their duration of release at specific temperatures. Generally, CRFs are placed in a laboratory dissolution system or a soil incubation system at a constant temperature to determine the duration of release. The amount of fertilizer released can be calculated since a known quantity of fertilizer is used. The CRF release period at the specified temperature is typically established when $80 \%$ to $90 \%$ of the fertilizer has been released. However, laboratory dissolution tests at constant temperatures cannot provide precise information about CRF release characteristics under field conditions where specific environmental temperatures can fluctuate widely within and between geographical locations.

The Virginia Tech Extraction Method (VTEM) and saturated media extract (SME) have been used to assess the nutritional status

Received for publication 20 Nov. 2003. Accepted for publication 25 Jan. 2005.

${ }^{1}$ Director, R\&D. To whom reprint requests should be addressed.

${ }^{2}$ Senior research specialist.

${ }^{3}$ Former senior scientist, retired. Current address: 17800 Timber Ln, Marysville, OH 43041. of container plants under field conditions (Warnke, 1975, 1988; Wright, 1984; Yeager et al., 1983). Nutritional guidelines have been developed based on the nutrient levels measured in the leachate or filtrate from these and other extraction methods (for review, see Peterson and Bilderback, 1986). The values obtained depend on CRF release rate, application rate, extent of leaching and plant nutrient uptake. Therefore, media extract values cannot be attributed solely to CRF release rate. In addition, since extraction methods do not capture all released nutrients from CRFs, the cumulative amount of nutrients released or remaining at any one time cannot be determined.

Container leachate analysis has been used extensively to estimate nutrient efficiency and monitor water quality (Broschat, 1995; Cox, 1993; Mickelson et al, 1994; Hershey and Paul, 1982; Yeager and Cashion, 1993). Leachate analysis to estimate CRF release rates has been used to a lesser degree and has been limited to greenhouse or laboratory conditions. Patel and Sharma (1977) collected leachate from soil columns placed in an incubator to estimate CRF release rates at a constant temperature. Prasad and Woods (1971) used leachate analysis to estimate $\mathrm{N}$ release rates from CRFs in peat and sand under greenhouse conditions. Similarly, Cabrera (1997) considered $\mathrm{N}$ leach analysis a suitable indicator of CRF release rate using a peat-based substrate under greenhouse con- ditions. However, a system to evaluate CRF release rates under container nursery field conditions is needed.

The leach collection system involves the collection and analysis of all leachate solution that exits the drain holes of a nursery container. It was developed to combine the quantitative attributes of a laboratory dissolution technique with the field applicability of substrate extraction methods in quantifying release characteristics of CRFs. A CRF release profile can be defined as the response curve generated by plotting release rate vs. time.

The objective of this research was to describe and evaluate the leach collection system for tracking fertilizer release rates under nursery conditions from a polymer-coated CRF.

\section{Materials and Methods}

A leach collection unit (LCU) was assembled by placing a standard nursery container through a $15.2-\mathrm{cm}$-diameter hole cut in the lid of 7.6-L black poly bucket (Plastican Inc. Dallas, Texas) (Fig. 1A and B). An injection molded 2.8-L nursery container (Poly-tainer \#1; Nursery Supplies, Inc., Chambersburg, $\mathrm{Pa}$.) was placed into the lid and slid into position such that about $2.5 \mathrm{~cm}$ of the bottom of the nursery container protruded through the lid deep enough so that all drain holes were beneath the collection bucket lid. The nursery container was plastic welded to the lid of the collection bucket using a 0.4-cm-diameter HDPE plastic welding rod and a plastic welding gun (Kamweld Corp., Norwood, Mass.). The container was welded on both the top and bottom sides of the lid. A circular disk $(15.2 \mathrm{~cm}$ diameter $\times 2.5 \mathrm{~cm}$ height) cut from bulk filter media (Patio Garden Pond, Moore, Okla.) was placed in the bottom of the nursery container to cover the drain holes, filter the leachate solution and retain substrate.

Osmocote $18.0 \mathrm{~N}-2.6 \mathrm{P}-9.9 \mathrm{~K}$, an 8 to 9 month product at $21{ }^{\circ} \mathrm{C}$ (The Scotts Co., Marysville, Ohio), was used as the polymercoated CRF. The leach collection system was evaluated at Scotts CRF Nursery Research Areas in Marysville, Ohio, and Apopka, Fla. Locally available bark-based potting substrates were used to evaluate the leach collection system at both locations (Florida Potting Soil Inc., Apopka, $45 \%$ pine bark, $45 \%$ peat, $10 \%$ sand (by volume), pH 6.9; Kurtz Bros. Inc., Independence, Ohio, KB Container Mix, pine bark, biosolid, sand, pH 6.2). Because organic components may affect the nutrient content of leachate (immobilization or ion exchange), locally available, inert quartz medium sand was included for comparison in Florida (Florida Potting Soil Inc., G-1 Greensmix, 0.25 to 0.5 $\mathrm{mm}, \mathrm{pH}$ 5.9, CEC 1.1) and Ohio (Millwood \#7; Central Silica Co., Zanesville, Ohio; 0.25 to $0.5 \mathrm{~mm}, \mathrm{pH} 8.2$, CEC 0.6). Osmocote was hand-mixed into the potting substrate at 25.6 $\mathrm{g} /$ pot to provide $1.8 \mathrm{~kg} \mathrm{~N} / \mathrm{m}^{3}$. A $9 \times 9$ mesh screen (Phifer Wire Products, Tuscaloosa,Ala.) cut into $30 \mathrm{~cm}$ squares was placed over each nursery container after the CRF was applied. The mesh screen was secured with a rubber band $(17.8 \mathrm{~cm}$ length $\times 0.63 \mathrm{~cm}$ width $\times 0.16$ 


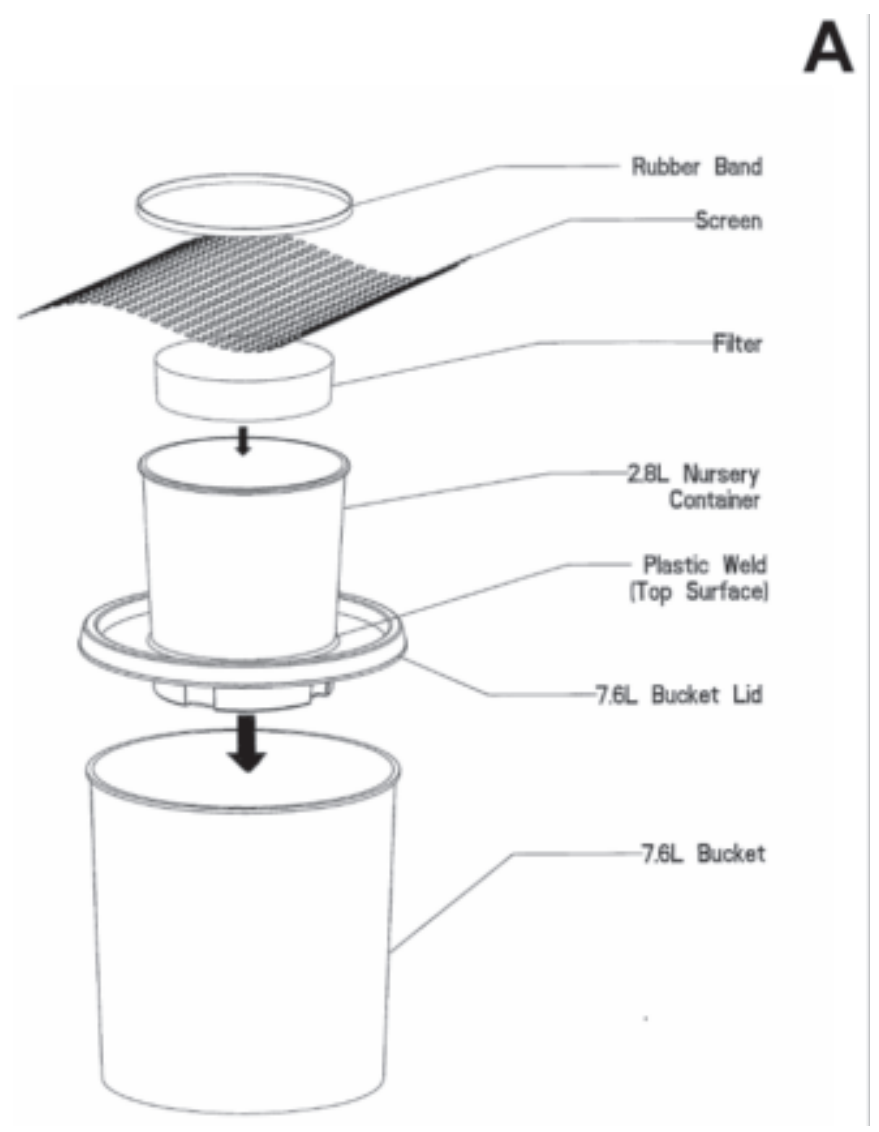

Fig. 1. The leach collection unit (LCU) showing (A) components and assembly and (B) the completed LCU.

cm thick, Aero Rubber Company, Inc., Bridgeview, Ill.) to prevent the loss of sand and CRF during heavy rainfall.

The LCU were placed in the nursery research areas on 22 Mar. in Apopka and 10 May 2000 in Marysville. The units were subjected to rainfall and similar volumes of overhead irrigation was applied as that used to produce a crop of adjacently located container grown woody ornamentals. Treatments were arranged in a completely randomized design with four replications, one LCU per replication.

After $7 \mathrm{~d}$ and 14-d intervals thereafter, the LCU were irrigated by hand with an additional $2.5 \mathrm{~cm}$ of water (leaching fraction $>0.75$ ) to ensure a final leaching of released nutrients before sampling the leachate solution. The lids of the LCU were removed after allowing the pots to drain for about $1 \mathrm{~h}$, the leachate volume recorded, a $20 \mathrm{~mL}$ sample collected for $\mathrm{N}$ analysis and the remaining leachate discarded. The concentration of total $\mathrm{N}$ in the solution was determined using an elemental analyzer (model 7000; Antek Instruments Inc., Houston, Texas). Total $\mathrm{N}$ was calculated for each collection interval by multiplying $\mathrm{N}$ concentration $\times$ leachate volume. Each value was divided by the number of days in the sampling interval to obtain daily leach rate. Cumulative $\mathrm{N}$ released was calculated by summing total $\mathrm{N}$ recovered for each interval. Following the last sampling in Ohio, all Osmocote granules were carefully hand-picked from the LCU to determine the amount of unreleased $\mathrm{N}$ remaining in the granules. The granules were crushed using a mortar and pestle in about $0.3 \mathrm{~L} \mathrm{DI}$ water, filtered (Whatman \#4) and DI water added to obtain $1.0 \mathrm{~L}$ solution. The solution was analyzed for total $\mathrm{N}$ using the elemental analyzer and the remaining $\mathrm{N}$ calculated as a percent of total $\mathrm{N}$ applied to each LCU.

Container temperatures. Substrate temperature in the LCU was recorded throughout the 2000 growing season at both locations using a datalogger equipped with type $T$ thermocouple probes (Campbell Scientific Inc., Logan, Utah). A probe was placed in the center of a sand-filled LCU in each location. For comparison, a probe was placed in the center of a 5.8-L container filled with bark-based substrate and planted with a Rhododendron $\times$ indica 'Southern Charm' liner in Florida, and Ilex $\times$ meserveae 'Blue Girl' liner in Ohio. Plants were grown as part of another study. Azalea and holly plants were fertilized with Osmocote Plus 15-3.9-9.9 (Scotts Co.), using a 12 to 14 and 8 to 9 month (21C) product, respectively, which produced vigorous plant growth throughout the season. Temperatures were recorded every $2 \mathrm{~h}$ and the average daily temperature calculated using the 12 values collected each day.

Statistical methods. Leachate curves obtained via replicated testing, under the same experimental conditions, form a sample from the totality of fertilizer release curves associated with the particular experimental setting. The totality of fertilizer release curves can be statistically modeled by Dirichlet processes and more generally mixtures of Dirichlet Processes (Antoniak, 1974). These processes are general enough to encompass the multivariate probabilistic structure and the constraints associated with the data collection scheme employed in the experiment. More specifically, mixtures of Dirichlet processes provide a general modeling framework for grouped data, typically obtained by sampling points from each of a collection of random sample functions from some common family of distribution functions.

The basic assumption underlying the mixture of Dirichlet Processes models, as it relates to this experimental framework, is that replicated leachate curves are sample distribution functions (i.e., nondecreasing, right-continuous functions), varying around some common parametric distribution function, $M(t)$, which represents the mean release function for the process. For the purposes of this paper, $\mathrm{M}(\mathrm{t})$ is assumed to be a mixture of two gamma distributions, each with a shape parameter and a scale parameter. The two distributions in the mixture represent the release functions for imperfectly coated and coated nitrogen, respectively. The final component of $\mathrm{M}(\mathrm{t})$ is the proportion of imperfectly coated nitrogen. The five parameters (the shape and scale parameter for each component plus the mixture parameter) of $\mathrm{M}(\mathrm{t})$ provide an abundance of flexibility with regard to the shape of $M(\mathrm{t})$. Finally, the degree to which the observed sample leach curves can deviate from $M(\mathrm{t})$ is determined by one last parameter, $\alpha_{0}$, which is typically referred to as the base-mass for the Dirichlet process. Values of $\alpha_{0}$ close to 0 allow the observed leachate curves to deviate from $M(\mathrm{t})$ in completely arbitrary ways, thus resulting in a completely flexible model, while values of $\alpha_{0}$ approaching infinity amount to perfectly smooth leach curves, reducing the flexibility of the model. 
Cumulative $\mathrm{N}$ leach data for each substrate $\times$ location combination was modeled using the Markov chain Monte Carlo sampling with 25,000 iterates. The model was selected once the mean release time, shape, proportion of imperfectly coated $\mathrm{N}$ and the scale parameters converged to specific values. These three quantities completely characterized the estimated fertilizer release distribution. The nitrogen release rate distribution is described as follows:

$P_{1, m} *\left(1-e^{\frac{\lambda}{3}}\right)+P_{w s} * \int_{0}^{\infty} \frac{\lambda}{\Gamma(r)}(\lambda x)^{r-1} e^{-\lambda} d x$

where $\mathrm{P}_{\text {im }}=$ proportion of imperfectly coated $\mathrm{N}$, $\mathrm{x}=$ days, $\mathrm{P}_{\mathrm{NR}}$ is the proportion of nonrecoverable $\mathrm{N}, \lambda=$ the coated $\mathrm{N}$ proportion density, $\Gamma$ $=$ the gamma distribution, and $\mathrm{r}$ is the coated mean release time. For each model, estimates with $95 \%$ tolerance bands were determined for coated $\mathrm{N}$ mean release time, imperfectly coated proportion and coated $\mathrm{N}$ proportion density. Differences between two estimates were not considered significant if either of the two estimates was within the tolerance band of the other estimate.

\section{Results}

Osmocote $18.0 \mathrm{~N}-2.6 \mathrm{P}-9.2 \mathrm{~K}$ release profiles, defined as the response curve of $\mathrm{N}$ leach rate versus time, were similar in sand or bark-based potting substrate in Ohio (Fig. 2) and Florida (Fig. 3). Two components were evident in the Osmocote release profile: 1) an imperfectly coated fraction providing early (within $30 \mathrm{~d}$ after potting) $\mathrm{N}$ release and 2) a coated fraction providing long term release. The imperfectly coated $\mathrm{N}$ proportion did not differ between sand and media in Ohio, about $20 \%$ of total $\mathrm{N}$ applied (Table 1). In Florida, $16 \%$ of the total $\mathrm{N}$ from imperfectly coated granules was captured when sand was used, compared to only $7 \%$ when the Florida bark substrate was used. The coated $\mathrm{N}$ mean release time for Osmocote $18.0 \mathrm{~N}-2.6 \mathrm{P}-9.2 \mathrm{~K}$ was 124 DAP using a bark-based substrate in Ohio, similar to 118 DAP when sand was used as the substrate (Table 1). Similarly, substrate did not affect coated $\mathrm{N}$ mean release time in Florida, about 105 DAP for both substrates. Overall, coated $\mathrm{N}$ mean release time was 2 weeks longer in Ohio than in Florida regardless of potting substrate used. Substrate and location did not affect coated $\mathrm{N}$ proportion density (range 9 to 12). Except for the initial $\mathrm{N}$ release from the imperfectly coated fraction, $\mathrm{N}$ leach rate curves (Figs. 2 and 3B and D) exhibited a bell-shaped pattern and sigmoidal cumulative leach curves (Figs. 2 and $3 \mathrm{~A}$ and $\mathrm{C}$ ).

Cumulative $\mathrm{N}$ recovered in the leachate was generally lower in bark-based substrates in Ohio and Florida. After 175 DAP in Ohio, cumulative $\mathrm{N}$ recovered in the leach solution was $61 \%$ with sand as the substrate, and 51\% with bark-based substrate. An additional $36 \%$ and $29 \%$ of the total applied $\mathrm{N}$ was recovered in the prills in sand and bark substrate respectively. Total $\mathrm{N}$ recovered (cumulative $\mathrm{N}$ in leach solution + residual $\mathrm{N}$ in prills) in Ohio was $97 \%$ and $80 \%$ for sand and bark-based substrate, respectively. After 217 DAP in Florida, cumulative $\mathrm{N}$ recovered in the leach solution was $88 \%$ when sand was used and $70 \%$ when bark-based substrate was used.

The average daily temperatures for the sand-filled LCU were similar (daily average max. difference $<3{ }^{\circ} \mathrm{C}$ ) to container-grown plants monitored in adjacent studies in both Florida and Ohio (Fig. 4).
Bark-based Substrate
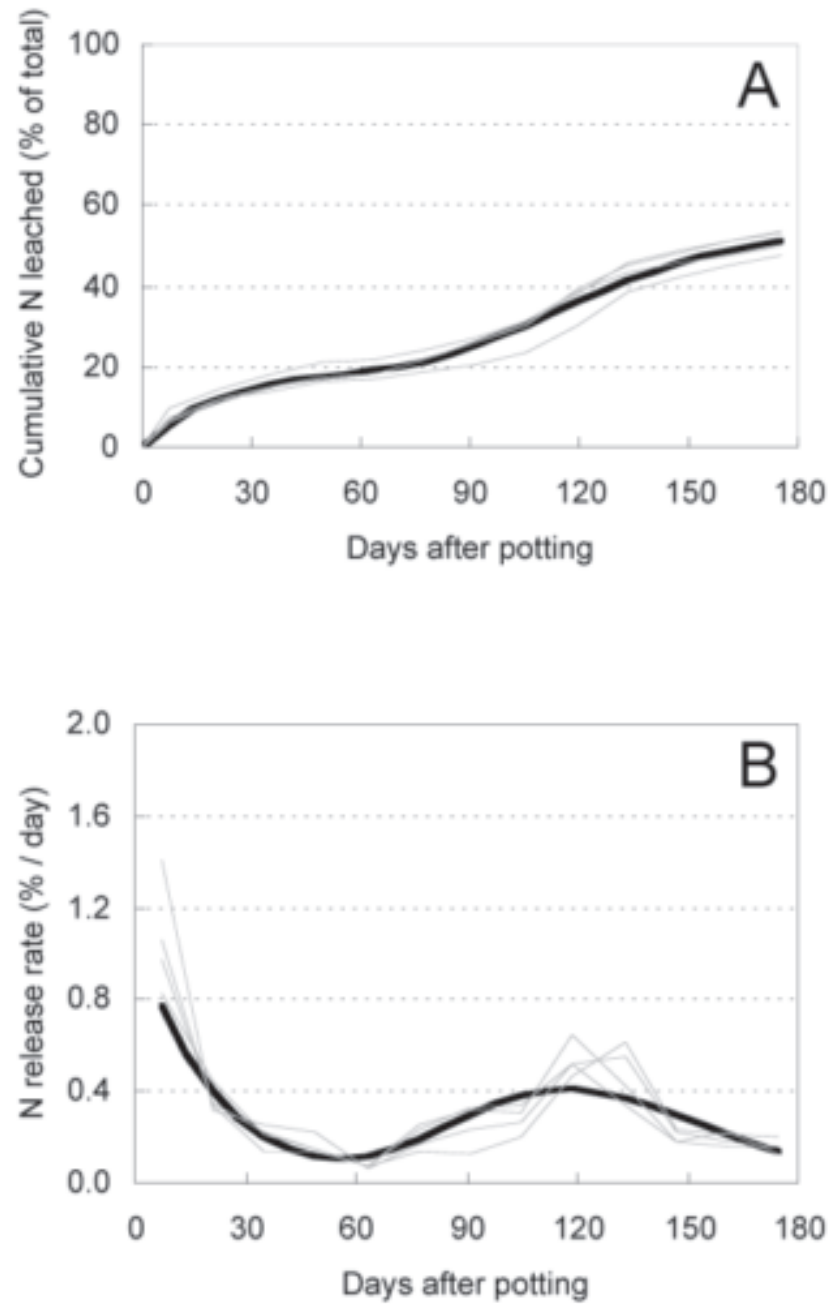

Sand Substrate
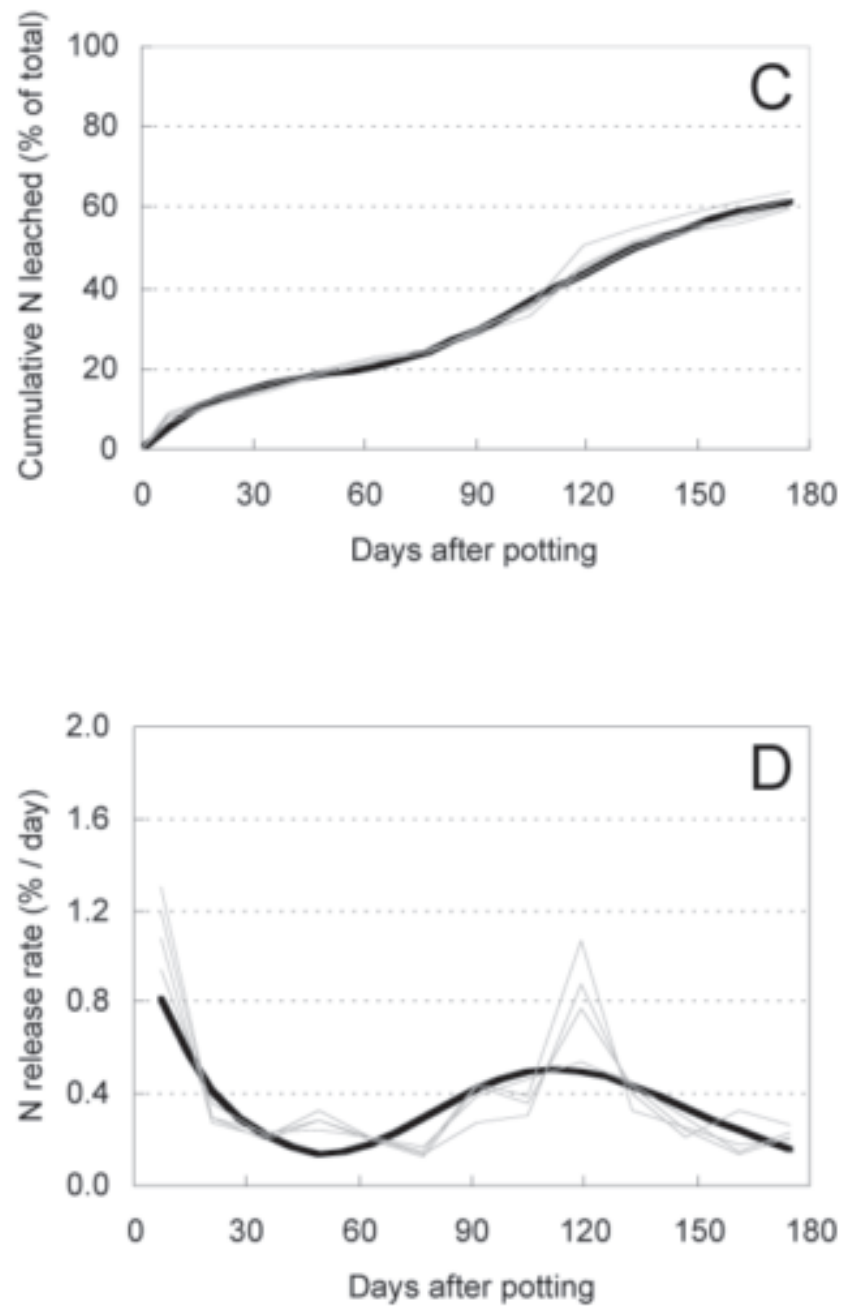

Fig. 2. Nitrogen leach rate from Osmocote 18.0N-2.6P-9.9K in Marysville, Ohio. Cumulative (A) and daily N leach rate (B) in bark-based substrate and cumulative (C) and daily $\mathrm{N}$ leach rate (D) in sand. Bold line is model, gray lines are replications. 
Bark-based Substrate
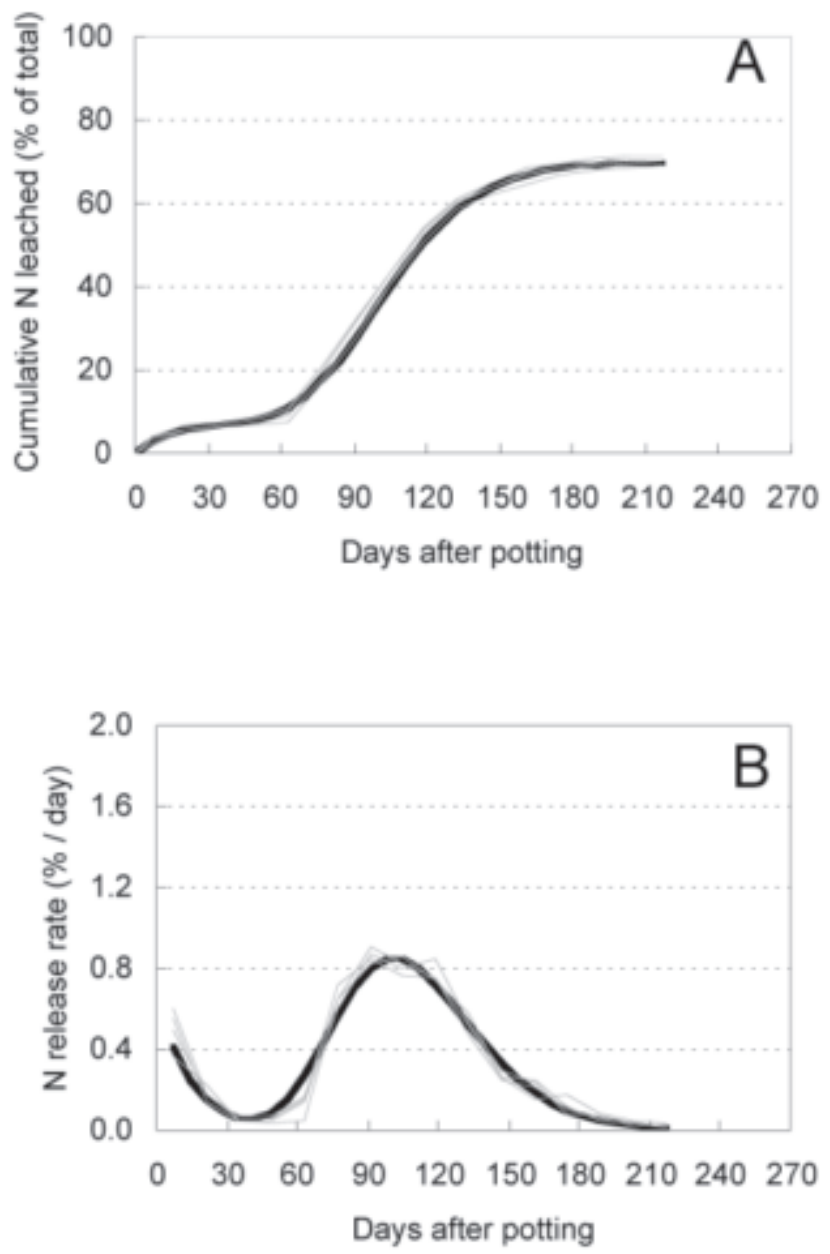

Sand Substrate
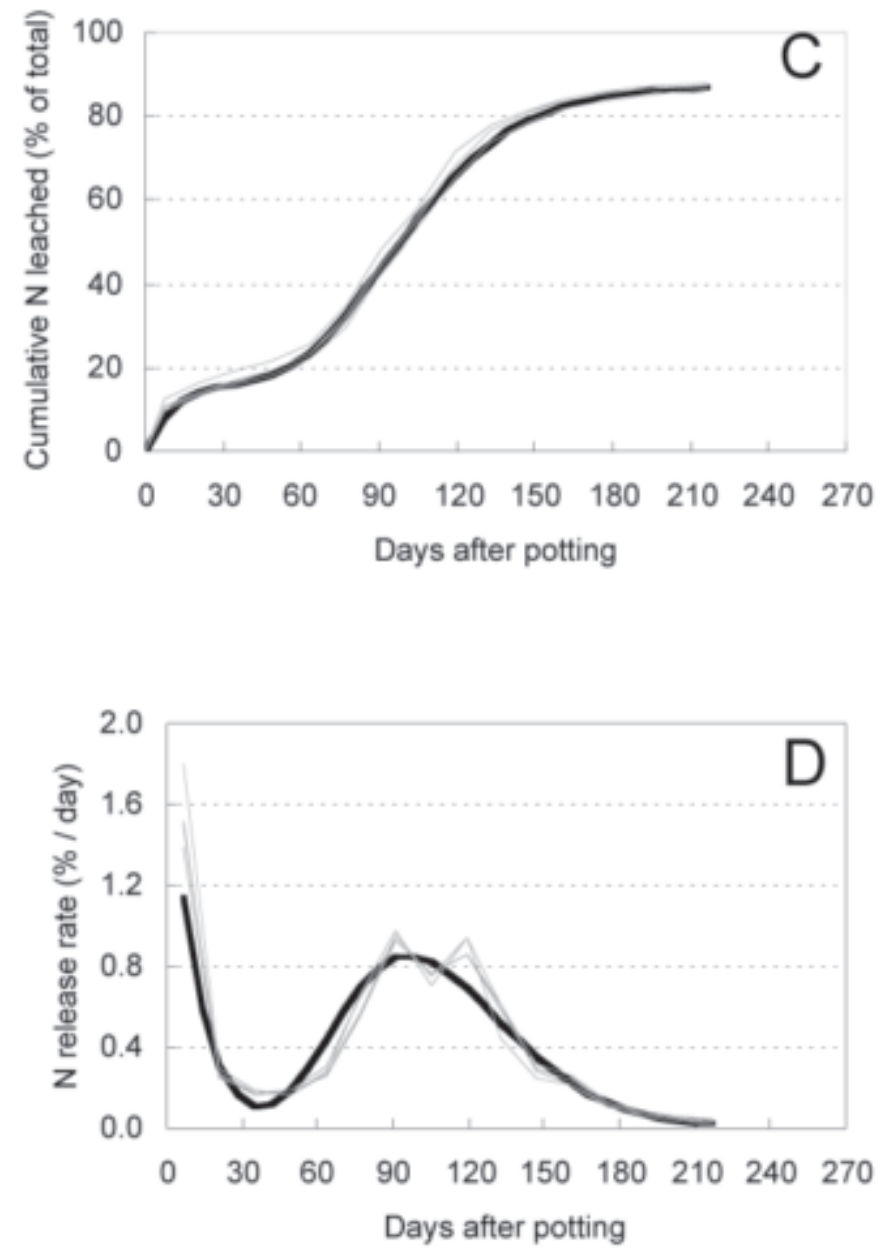

Fig. 3. Nitrogen leach rate from Osmocote 18.0N-2.6P-9.9K in Apopka, Fla. Cumulative (A) and daily N leach rate (B) in bark-based substrate and cumulative (C) and daily $\mathrm{N}$ leach rate $(\mathbf{D})$ in sand. Bold line is model, gray lines are replications.

\section{Discussion}

The goal of this research was to describe a device for tracking $\mathrm{N}$ release from a polymercoated CRF under container nursery conditions. The LCU was effective for monitoring the release ofCRF-N over an extended period of time. Osmocote $18.0 \mathrm{~N}-2.6 \mathrm{P}-9.9 \mathrm{~K}$ had similar $\mathrm{N}$ release profiles in both sand and bark-based substrates. The $\mathrm{N}$ leach rates, however, were slightly reduced at times in the bark-based substrates compared to sand. Lower $\mathrm{N}$ leach rates were not due to decreased $\mathrm{N}$ release from Osmocote because granules retrieved from the two substrates in Ohio contained similar amounts of $\mathrm{N}$ at the end of the test. Therefore, Osmocote granules released the same amount of total $\mathrm{N}$ during the test, but a reduced amount of $\mathrm{N}$ was capable of being leached through the bark-based substrate. This was presumably due to $\mathrm{N}$ immobilization since bark-based substrates used for container nursery plant production, including those used in this research, are composed largely of uncomposted materials. In addition, Osmocote release rate is driven largely by substrate temperature (Lunt and Oertli, 1962; Oertli and Lunt, 1962). It is not affected by substrate chemical and physical characteristics such as $\mathrm{pH}$, microbial activity, water holding capacity or porosity. Results from this research indicate that sand did not fundamentally change Osmocote N release rate compared to bark-based substrate. This concurs with Prasad and Woods (1971), in which the release rate of Osmocote was unchanged in peat or sand.

Although $\mathrm{N}$ release from Osmocote in bark-based substrates was similar to sand, we recommend sand as the substrate in the leach collection system. Sand provides a more consistent substrate material so that CRF release curves from various years and locations can be compared without the potential confounding factor of substrate variability. In addition, total $\mathrm{N}$ recovered in the leachate solution routinely

Table 1. Markov chain model estimates and $95 \%$ tolerance limits for cumulative nitrogen leached from Osmocote $18 \mathrm{~N}-2.6 \mathrm{P}-9.9 \mathrm{~K}\left(8\right.$ to 9 months $\left.21^{\circ} \mathrm{C}\right)$ placed in a leach collection system using bark-based and sand potting substrates in Marysville, Ohio and Apopka, Fla.

\begin{tabular}{|c|c|c|c|c|c|c|}
\hline \multirow[b]{3}{*}{ Parameter } & \multicolumn{3}{|c|}{ Ohio } & \multicolumn{3}{|c|}{ Florida } \\
\hline & \multirow[b]{2}{*}{ Estimate } & \multicolumn{2}{|c|}{ Tolerance limit } & \multirow[b]{2}{*}{ Estimate } & \multicolumn{2}{|c|}{ Tolerance limit } \\
\hline & & Lower & Upper & & Lower & Upper \\
\hline \multicolumn{7}{|c|}{ Imperfectly coated $\mathrm{N}$ proportion ( $\%$ of total $\mathrm{N}$ applied) } \\
\hline Sand & 20.8 & 16.8 & 24.8 & 16.5 & 14.5 & 18.6 \\
\hline \multicolumn{7}{|c|}{ Coated $\mathrm{N}$ mean release time (days after potting) } \\
\hline Bark & 123.6 & 117.8 & 129.4 & 106.3 & 104.2 & 108.3 \\
\hline Sand & 118.4 & 111.3 & 125.2 & 104.2 & 101.6 & 106.6 \\
\hline Sand & 11.0 & 7.8 & 16.2 & 9.1 & 8.0 & 15.2 \\
\hline
\end{tabular}




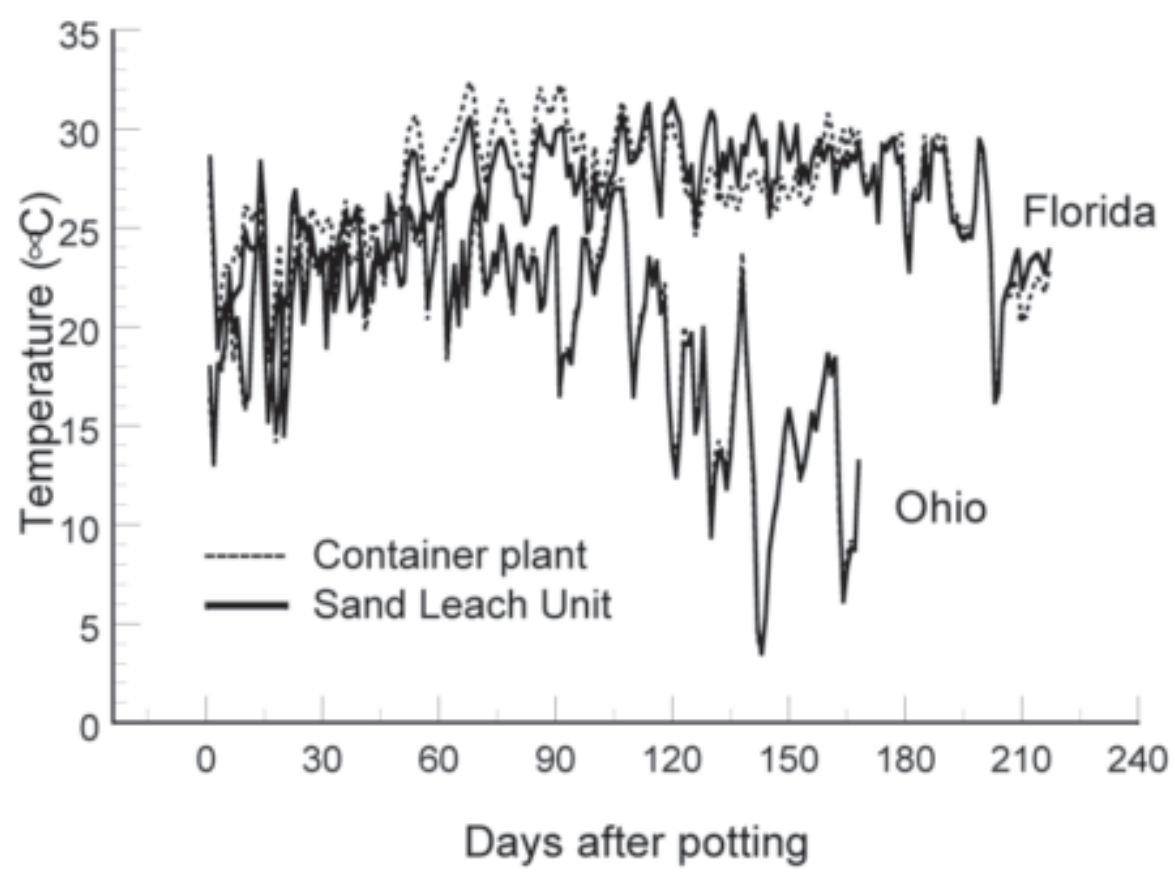

Fig. 4. Daily substrate container temperatures during the 2000 growing season for a holly plant and a sand-filled leach collection unit (LCU) in Marysville, Ohio, and an azalea plant and a sand-filled LCU in Apopka, Fla. Each data point is the average of 12 readings per day.

exceeds $90 \%$ if the test duration is sufficient to achieve complete CRF release, or if the unreleased CRF-N is determined. Finally, N leach rate in sand is a better estimate of the actual $\mathrm{N}$ release from the CRF since immobilization or ion exchange is minimal. Since microbial activity could be reduced in sand relative to bark-based substrates, the release characteristics of microbial-dependent CRFs, such as sulfurcoated urea, polymer-coated sulfur coated urea, and methylene ureas, may be altered in sand compared to a bark-based substrate.

Although the sand LCU were somewhat more exposed to direct sunlight compared to plants monitored in the study, the average substrate temperature of the sand LCU was similar to potted azalea or holly plants. This agrees with past years of monitoring LCU substrate temperatures and various potted plant substrate temperatures (data not shown). The LCU can also be placed among container-grown plants to reduce possible microsite environmental conditions.

A technique to quantify the nutrient release rates of polymer-coated CRFs in nursery conditions provides many benefits. Manufacturers can use this information to 1) develop new CRF products based on quantitative field data, 2) substantiate product claims regarding product longevity, 3) quantify fertilizer release rates under field conditions, and 4) develop quality be determined, rather than using the response of container plants to determine the fertilizer release characteristic. Finally, crop nutrient content can be estimated by comparing nutrient content of leachate from LCU with and without plants. Ahistorical record would guide nursery managers as to the best time for efficient CRF application or release profile.

\section{Literature Cited}

Antoniak, C.E. (1974). Mixtures of Dirichlet Processes with applications to Bayesian nonparametric problems. Ann. Stat. 2:1152-1174.

Broschat, T.K. 1995. Nitrate, phosphate, and potassium leaching from container-grown plants fertilized by several methods. HortScience 30:74-77.

Cabrera, R.I. 1997. Comparative evaluation of nitrogen release patterns from controlled-release fertilizers by nitrogen leaching analysis. HortScience 32:669-673.

Cox, D.A. 1993. Reducing nitrogen leaching-losses from containerized plants: The effectiveness of controlled release fertilizers. J. Plant Nutr. 16:533-545.

Hershey, D.R. and J.L. Paul. 1982. Leaching-losses of nitrogen from pot chrysanthemums with controlled release or liquid fertilization. Sci. Hort. 17:145-152.

Lunt, O.R. and J.J. Oertli. 1962. Controlled release fertilizer minerals by incapsulating membranes: II. Efficiency of recovery, influence of soil moisture, mode of application, and other considerations related to use. Soil Sci. Soc. Amer. Proc. 26:584-587.

Mikkelson, R.L., H.M. Williams, and A.D. Behel Jr. 1994. Nitrogen leaching and plant uptake from controlled release fertilizers. Fert. Res. $37: 43-50$.

Oertli, J.J. and O.R. Lunt. 1962. Controlled release of fertilizer minerals by incapsulating membranes: I. Factors influencing the rate of release. Soil Sci. Soc. Amer. Proc. 26:579-583.

Patel, A.J. and G.C. Sharma. 1977. Nitrogen release characteristics of controlled-release fertilizers during a four month soil incubation. J. Amer. Soc. Hort. Sci. 102:364-367.

Peterson, J.C. and T.E. Bilderback. 1986. Interpretation of extraction and nutrient determination procedures for organic potting substrates. HortScience 21:213-232.

Prasad, M. and M.J. Woods. 1971. Release characteristics of nitrogen fertilizers in peat and sand. J. Agr. Food Chem. 19:96-98.

Warnke, D.D. 1975. Greenhouse soil testing. Paper presented to 5th Soil-Plant Anal. Wkshp, Bridgeton, Mo.

Warnke, D.D. 1988. Recommended test procedure for greenhouse growth media, p. 34-37. N.Dak. Agr. Expt. Sta. N. Central Reg. Publ. 221.

Yeager, T.H., R.D. Wright, and S.S. Donohue. 1983. Comparison of pour-through and saturated pine bark extract, N, P, K, and $\mathrm{pH}$ levels. J. Amer. Soc. Hort. Sci. 108:112-114.

Yeager, T.H. and G. Cashion. 1993. Controlled release fertilizer affects nitrate nitrogen runoff from container plants. HortTechnology 3:174-177. 